\title{
ОБОСНОВАНИЕ СТРУКТУРЫ И СОСТАВА СИСТЕМ ВОДООЧИСТКИ НА ОСНОВЕ ОЦЕНКИ УРОВНЯ АВТОМАТИЗАЦИИ ТЕХНОЛОГИЧЕСКИХ ПРОЦЕССОВ
}

\section{В. Н. Шmепа ${ }^{1}$, Н. А. Заец, ${ }^{2}$ О. Н. Прокопеня ${ }^{3}$, А. Н. Желновач4}

${ }^{1}$ К. т. н., доцент, доцент кафедры высшей математики и информационных технологий Полесского государственного университета,

Пинск, Беларусь, е-mail: shns1981@gmail.com

${ }^{2}$ К. т. н., доцент, доцент кафедры автоматики и робототехнических систем им. акад. И. И. Мартьненко Национального университета биоресурсов и природопользования Украины, Киев, Украина

${ }^{3}$ К. т. н., доцент, заведующий кафредрой автоматизации технологических процессов и производств Брестского государственного технического университета, Брест, Беларусь

${ }^{4}$ К. т. н., доцент, доцент кафредры экологии Харьковского национального автомобильно-дорожного университета, Харьков, Украина

\section{Ресерат}

Исследована зависимость эффрективности работы системы водоочистки от уровня автоматизации отдельных подсистем. Исследование эффективности проводилось методом экспертных оценок для реальных систем из различных отраслей промышленности. Установлено, что отдельные подсистемы оказывают различное влияние на качество очистки сточных вод. При этом эффективность работы системы очистки существенно зависит от взаимного влияния отдельных подсистем, что необходимо учитывать при выборе структуры и состава системы автоматизации.

Ключевые слова: эффективность водоочистки, подсистема, качество очистки сточных вод, автоматизация.

\section{SUBSTANTIATION OF STRUCTURE AND COMPOSITION OF THE WATER TREATMENT SYSTEMS BASED ON ASSESSMENT OF AUTOMATION LEVEL OF TECHNOLOGICAL PROCESSES}

Abstract

\section{M. Shtepa, N. A. Zaets, O. N. Prokopenya, A. N. Gelnovach}

The dependence of the efficiency of the water treatment system on the level of automation of individual subsystems is investigated. The study of efficiency was carried out by the method of expert evaluations for real systems from various branches of industry. It has been established that individual subsystems have a different effect on the quality of wastewater treatment. Moreover, the efficiency of the cleaning system depends significantly on the mutual influence of individual subsystems, which must be taken into account when choosing the structure and composition of the automation system.

Keywords: efficiency of water treatment, subsystem, quality of waste water treatment, automation.

\section{Введение}

Ключевыми параметрами качества сточных вод, контролируемых соответствующими органами, являются [1, 2]: азот аммонийный, биологическое потребление кислорода (БПК $)$, водородный показатель (рН), взвешенные вещества, железо, нефтепродукты, нитриты, нитраты, химическое потребление кислорода (ХПК), фосфаты, хлориды, синтетические поверхностно-активные вещества (СПАВ), сульфраты. Химический анализ других показателей проводится при необходимости с учетом специфики предприятия - как правило, анализы дополняются несколькими показателями.

Концептуальные вопросы экологической безопасности в контексте построения систем водоочистки, рассматривались такими специалистами, как Ф.И. Гончаров, М. Ф. Реймерс, Г. А. Белявский, Ю. А. Израэль, И. П. Крайнов и другими $[3,4]$.

В рамках унисфикации международного законодательства была принята Директива 2000/60/ЕС Европарламента и Совета Европы, принципы для действий сообщества в области водной политики - Рамочная Директива о воде (Water Frame Directory, WFD) [5]: методология оценки экологического статуса в рамках 5- классовой системы. Важнейший принцип этой рамочной директивы ЕС вне зависимости от того, соответствует ли вода в водоеме нормативу или нет, заключается в том, что нельзя допускать ухудшения ее качества и нельзя допускать повышения объема сбросов загрязнителей в водоем; каждый новый сброс необходимо компенсировать снижением объема существующих.

Однако в документе не представлены подходы к выбору технологического оборудования водоочистки. Такой выбор рекомендуется выполнять согласно Best available technology (BAT), где, как и в Texническом кодексе установившейся практики (ТКП), нет методических обоснований оптимального выбора схем систем водоочистки и уровня их автоматизации [5].

Именно поэтому актуальной задачей является обоснование новых подходов к выбору структуры и состава систем водоочистки, а также функций, реализуемых системой автоматизации.

\section{Постановка задачи}

На основе оценки значимости автоматизируемых функций необходимо обосновать рациональный уровень их автоматизации и выбрать структуру системы управления, при которой обеспечивается взаимосвязь между отдельными подсистемами, обеспечивающая наиболее эфффективное функционирование всей системы водоочистки.

\section{Материалы и методика исследований}

С учетом многофакторности и нелинейности изменения параметров сточных вод [2] можно рассматривать автоматическую систему управления (АСУ) технологическими процессами (ТП) водоочистки как эффективное средство согласования работы различных электро-технологических установок и повышения их эффеективности [6], особенно при рисках возникновения чрезвычайных ситуаций (ЧС) [1]. Однако для определения комплексов таких технических средств, на которых необходимо акцентировать внимание при автоматизации, целесообразно провести предварительную оценку степени автоматизации существующих установок.

Показатель уровня автоматизации $P$ определяется на основе декомпозиции всего управляющего процесса на отдельные функции управления. Для каждой $i$-ой функции задается коэффициент важности $\mathrm{Y}_{i}$, который определяет относительную важность функции управления в общем процессе управления и оценивает требуемую степень автоматизации данной функции.

Коэффициент $Y_{i}$ и оценка оптимального значения степени авто-

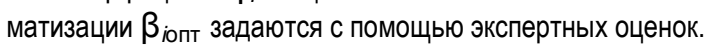

Перечень функций, для которых проведен такой анализ, выбран в соответствии с предложенным алгоритмом [2], а расчет степени автоматизации составлен на основе анализа действующей системы автоматизации объектов и инструкций оператора [6], характеризующих неавтоматизированную часть функций. 
Вестник Брестского государственного технического университета. 2020. №4

Например, для реализации функции «контроль ТП» системы водоочистки значение $\beta$ определяется следующим образом:

$$
\beta=\sum_{\gamma=1} \frac{\beta_{\gamma} n_{\gamma}}{n_{3}} .
$$

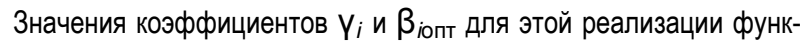
ции АСУ рационально принять соответственно 0,9 и 1.

Соответствие рассчитанной степени автоматизации его оптимальному значению:

$$
S=\frac{\beta}{\beta_{\text {опт }}} \cdot 100 \% .
$$

Аналогично определяется степень автоматизации для других функций действующих (проектируемых) технических средств систем водоочистки. В соответствии с методикой [2] и предложенным в ней алгоритмом выполнялись исследования отклонения существующего уровня автоматизации от оптимального для рассмотренных методов водоочистки (отдельно для каждого из них без интеграции в единый комплекс). На основе полученных результатов выполнялась комплексная экспертная оценка направлений структурного улучшения систем водоочистки.

Для репрезентативной оценки характеристик качества водосброса и выбора технических средств систем водоочистки выбрали предприятия из разных секторов реальной экономики:
- мясоперерабатывающая отрасль;

- деревоперерабатывающая отрасль;

- предприятие малой металлургии;

- производство продуктов бытовой химии (косметология).

Контролировались два параметра качества водосброса, которые характерны для всех выбранных предприятий: концентрация взвешенных частиц и концентрация азота аммонийного.

Задачей таких исследований систем водоочистки промышленных объектов являлось выявление типичных загрязнителей, залповое увеличение которых (нештатная ситуация) необходимо учесть при работе водоочистного оборудования.

\section{Анализ показателей качества водосброса промышленных} предприятий

Оценка качественных показателей систем водоочистки промышленных объектов разных отраслей (мясоперерабатывающее предприятие, деревоперерабатывающее предприятие, предприятие малой металлургии и предприятие производства продукции бытовой химии) продемонстрировала разнородность загрязнителей, вызванную различным технологическим использованием водных ресурсов.

Наличие грубой погрешности оценивалось по критерию Стьюдента. При этом были систематизированы типичные загрязнители, которые характерны для указанных предприятий и касаются четырех объектов (табл. 1).

\begin{tabular}{|c|c|c|c|c|c|c|c|c|}
\hline \multirow{2}{*}{$\begin{array}{l}\text { № } \\
\text { п/п }\end{array}$} & \multicolumn{2}{|c|}{$\begin{array}{c}\text { Мясоперерабатывающее } \\
\text { предприятие }\end{array}$} & \multicolumn{2}{|c|}{$\begin{array}{c}\text { Деревоперерабатывающее } \\
\text { предприятие }\end{array}$} & \multicolumn{2}{|c|}{$\begin{array}{c}\text { Предприятие малой } \\
\text { металлургии } \\
\end{array}$} & \multicolumn{2}{|c|}{$\begin{array}{c}\text { Предприятие производства } \\
\text { продукции бытовой химии }\end{array}$} \\
\hline & ВЧ, мг/л & $\mathrm{AA}, \mathrm{m} / \mathrm{л}$ & ВЧ, мг/л & $\mathrm{AA}, \mathrm{мг} / л$ & $\mathrm{BU}, \mathrm{Mr} / \Omega$ & $\mathrm{AA}, \mathrm{mг} / л$ & ВЧ, $\mathrm{Mг} / л$ & $\mathrm{AA}, \mathrm{mr} / \Omega$ \\
\hline 1 & 3455 & 37 & 1364 & 74 & 365 & 36 & 5334 & 123 \\
\hline 2 & 2856 & 43 & 1456 & 67 & 257 & 37 & 5231 & 137 \\
\hline 3 & 2647 & 51 & 1982 & 53 & 249 & 28 & 4129 & 67 \\
\hline 4 & 2364 & 31 & 2465 & 60 & 153 & 29 & 6201 & 53 \\
\hline 5 & 3871 & 34 & 1003 & 43 & 602 & 53 & 3257 & 102 \\
\hline 6 & 1534 & 39 & 975 & 49 & 577 & 26 & 5790 & 78 \\
\hline 7 & 1687 & 51 & 2471 & 82 & 421 & 33 & 2312 & 45 \\
\hline 8 & 1789 & 62 & 2147 & 49 & 234 & 34 & 3023 & 67 \\
\hline 9 & 2586 & 47 & 1972 & 51 & 678 & 38 & 4720 & 97 \\
\hline 10 & 3456 & 42 & 1870 & 44 & 423 & 40 & 5673 & 80 \\
\hline 11 & 2890 & 36 & 1783 & 39 & 499 & 43 & 3805 & 53 \\
\hline 12 & 2987 & 37 & 987 & 57 & 206 & 38 & 4597 & 62 \\
\hline 13 & 4237 & 43 & 1347 & 52 & 347 & 34 & 2156 & 58 \\
\hline 14 & 3984 & 53 & 1463 & 37 & 346 & 49 & 1869 & 42 \\
\hline 15 & 2041 & 57 & 1824 & 77 & 198 & 50 & 4687 & 59 \\
\hline 16 & 1475 & 54 & 1798 & 82 & 265 & 37 & 2349 & 67 \\
\hline 17 & 1243 & 37 & 2736 & 68 & 379 & 40 & 3574 & 98 \\
\hline 18 & 3897 & 39 & 2135 & 58 & 425 & 45 & 4239 & 82 \\
\hline 19 & 4712 & 42 & 2400 & 61 & 320 & 53 & 2017 & 74 \\
\hline 20 & 3471 & 47 & 2178 & 53 & 389 & 37 & 1164 & 63 \\
\hline 21 & 2147 & 50 & 1463 & 49 & 403 & 36 & 2497 & 58 \\
\hline 22 & 1870 & 37 & 1783 & 42 & 306 & 34 & 5724 & 83 \\
\hline 23 & 1400 & 52 & 896 & 59 & 256 & 59 & 4668 & 77 \\
\hline 24 & 1563 & 42 & 2793 & 62 & 242 & 47 & 5780 & 117 \\
\hline 25 & 987 & 38 & 1423 & 37 & 657 & 39 & 4237 & 64 \\
\hline 26 & 3412 & 39 & 2879 & 73 & 432 & 27 & 3338 & 58 \\
\hline 27 & 2789 & 47 & 2473 & 60 & 360 & 46 & 2786 & 67 \\
\hline 28 & 2104 & 56 & 2140 & 49 & 257 & 45 & 2347 & 75 \\
\hline 29 & 1902 & 48 & 2893 & 55 & 523 & 41 & 987 & 69 \\
\hline 30 & 3477 & 36 & 1230 & 63 & 467 & 53 & 6476 & 43 \\
\hline
\end{tabular}

Таблица 1 - Значения загрязнителей для исследуемых предприятий (среднесуточные показатели в течение месяца)

Примечание: ВЧ - взвешенные частицы, АА - азот аммонийный 


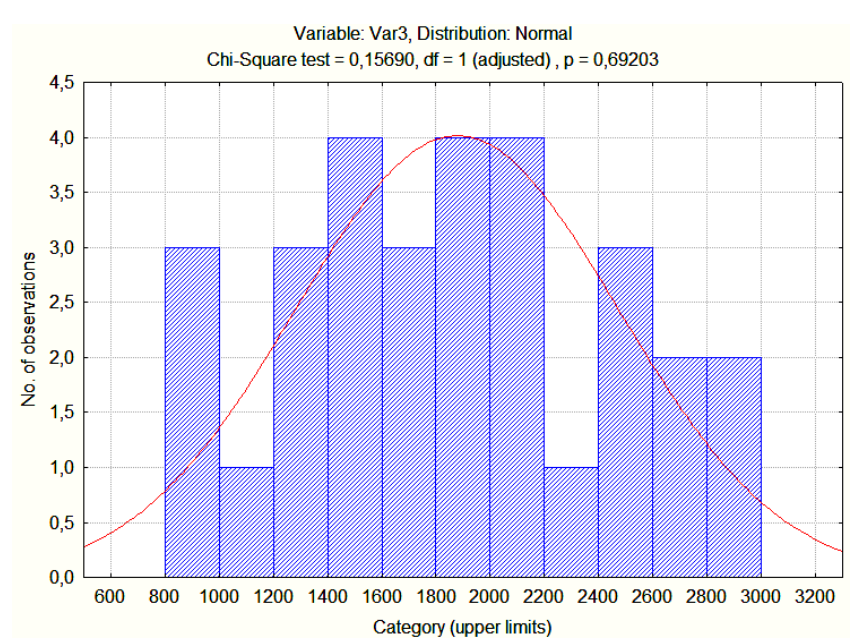

A)

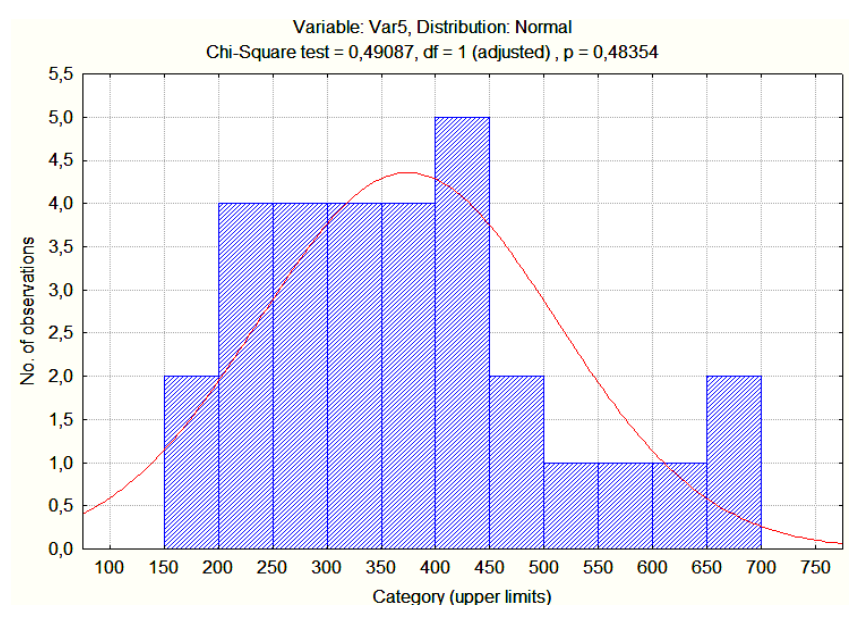

B)

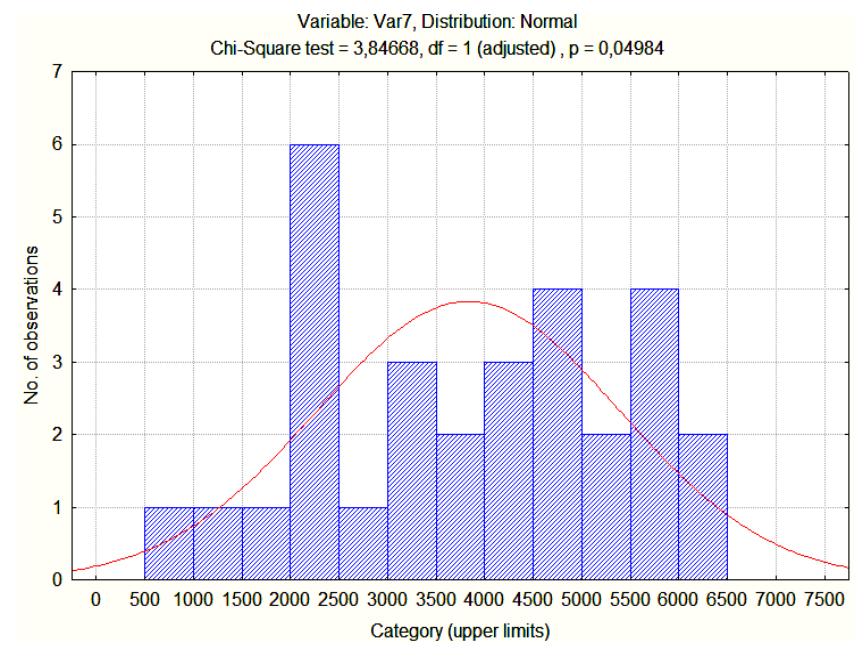

Д)

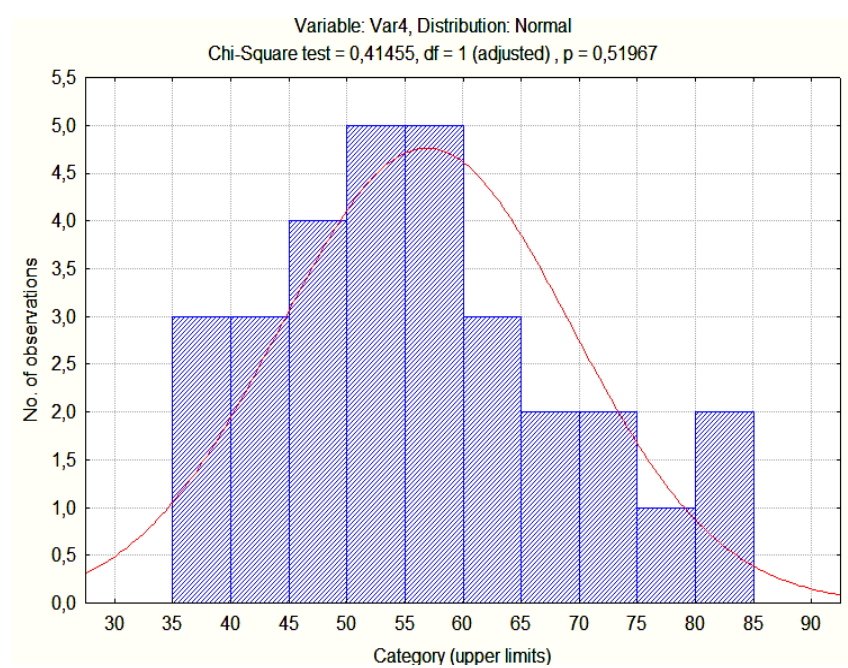

Б)

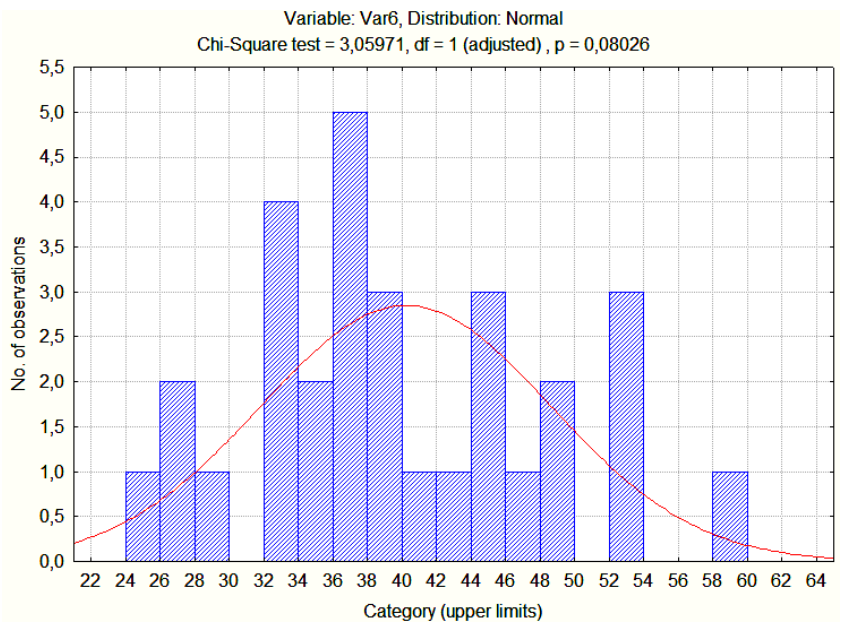

Г)

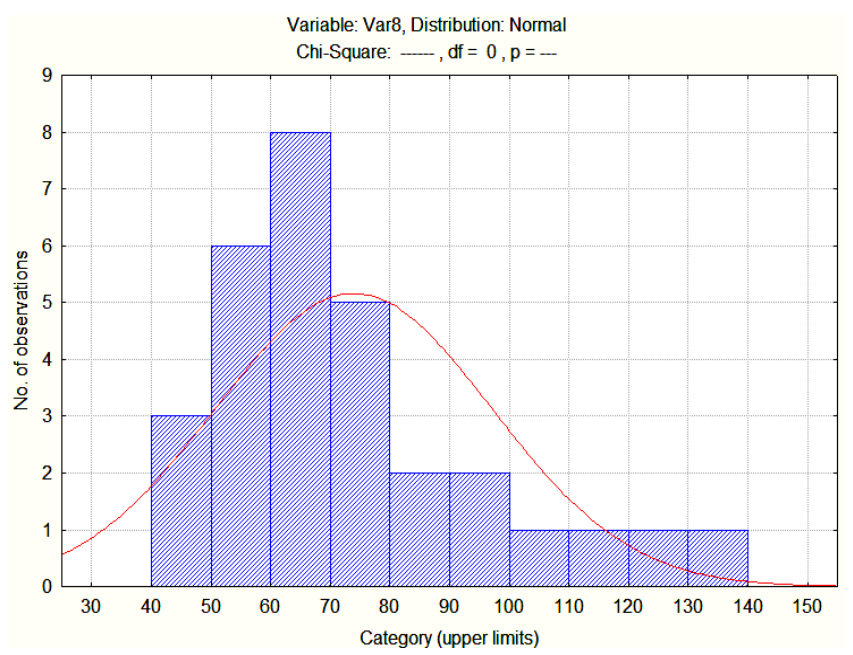

E) 


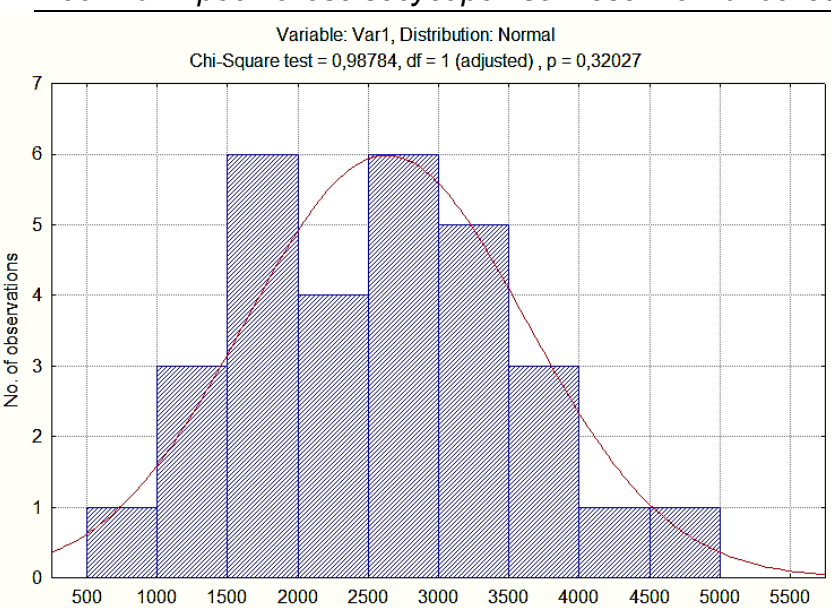

Ж)

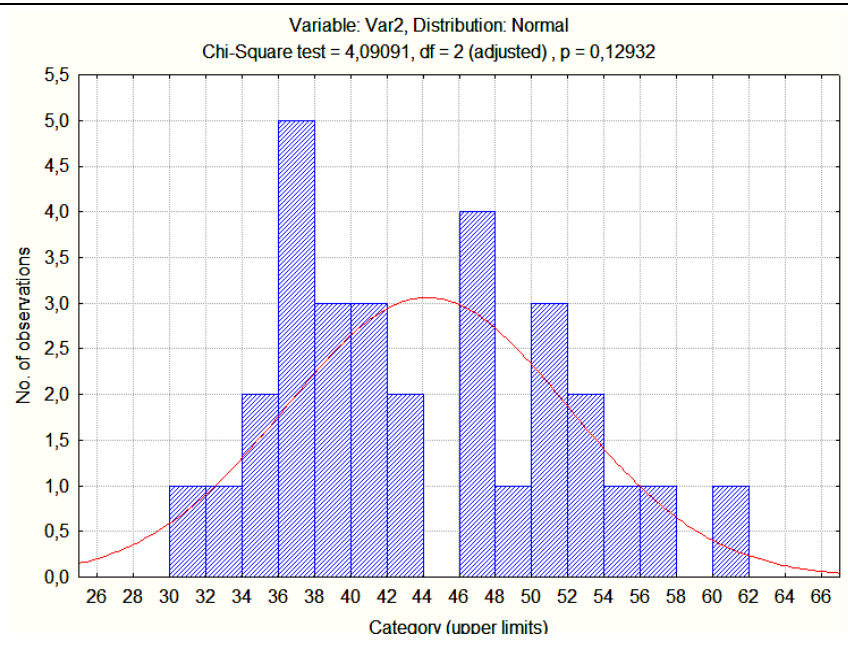

3)

A - концентрация ВЧ на предприятии мясопереработки, Б - концентрация АА на предприятии мясопереработки, В - концентрация ВЧ на предприятии деревопереработки, Г - концентрация АА на предприятии деревопереработки, Д - концентрация ВЧ на предприятии малой металлургии, E - концентрация АА на предприятии малой металлургии, Ж - концентрации ВЧ на предприятии бытовой химии, 3 - концентрация АА на предприятии бытовой химии

Рисунок 1 - Проверка на нормальность закона распределения выборок концентраций однотипных загрязнителей, полученных при анализе стоков предприятий

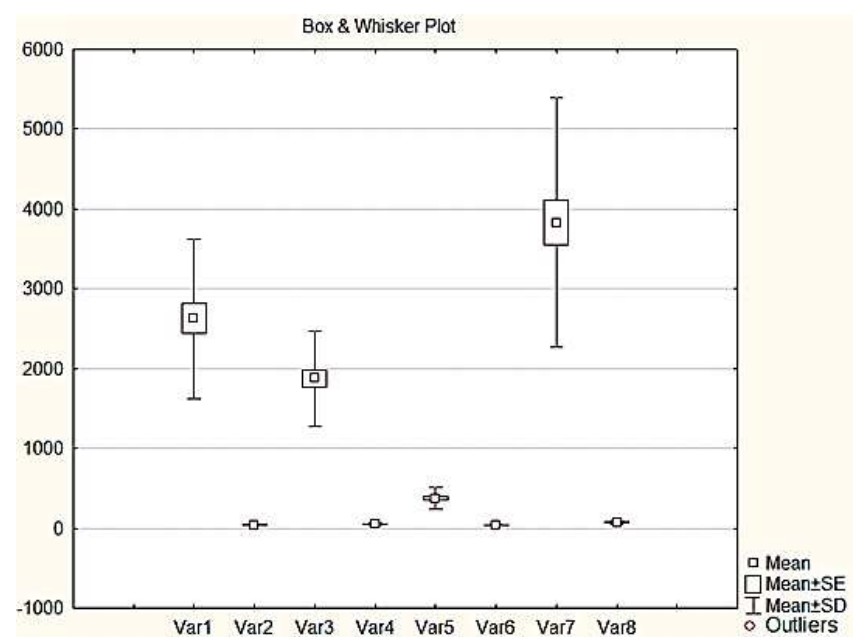

Var 1-8 - соответственно, концентрация ВЧ на предприятии мясопереработки, концентрация АА на предприятии мясопереработки, концентрация ВЧ на предприятии деревопереработки, концентрация АA на предприятии деревопереработки, концентрация ВЧ на предприятии малой металлургии, концентрация АA на предприятии малой металлургии, концентрация ВЧ на предприятии бытовой химии, концентрация АА на предприятии бытовой химии

Рисунок 2 - Оценка наличия статистических выбросов исследования выборок концентраций однотипных загрязнителей, полученных на реальных предприятиях (в качестве центральной точки выбрано среднее значение)

На основе анализа рисунка 2 можно утверждать, что выбросов, которые нужно было бы отсеивать, не обнаружено. В общем статистические исследования (см. рис.1, 2) показали, что для анализа значений показателей качества поступающей на очистку сточной воды нужно применять непараметрические подходы и разрабатывать технологические решения, способные работать в условиях нелинейных и нестационарных изменений концентраций загрязнителей.

Дальнейший выбор методов очистки стоков промышленных объектов разных отраслей выполнялся на основе СНиП 2.04.02-84, результатов собственных исследований и научно-технических наработок других авторов $[1-4,7-9]$.
Оценка уровня автоматизации технологических процессов систем водоочистки в контексте потенциальной оптимизации их структуры

Структура комбинированной электротехнологической системы водоочистки, уровень автоматизации которой оценивался, включает в себя (рис. 3) [8]: электрохимический комплект в составе рНкорректора и электрокоагулятора, электрохимический окислитель (оба с использованием ОРТА - оксид-рутений-титановых анодов), фильтр с плавающей пенополистирольной засыпкой, аэраторы и ёмкость-реактор.

На основе экспериментальных исследований по методике [8] были получены парные поагрегатные соответствия степени автоматизации ТП водоочистки их оптимальному значению (табл. 2).

Анализируя полученные результаты, можно сказать, что процессы с незначительным количеством операций и, что самое главное, наличием датчиков, контролирующих технологические параметры в режиме реального времени (фильтрация и аэрация), имеют значительное приближение к оптимальному значению степени автоматизации. Те же процессы, которые характеризуются многофакторностью и многостадийностью, достаточно далеки от оптимального показателя степени автоматизации: электрокоагуляция, рН-коррекция и особенно окисление (процессы там происходят при аппаратно-стабилизированных гидродинамических и электрических параметрах).

При этом среднее отклонение фактической степени автоматизации модулей водоочистного оборудования от оптимальных значений пяти рассмотренных методов (см. табл. 2) - 55,56\%.

На основе расчета степени автоматизации единого комплекса электротехнических средств (см. рис. 3), включая выбранные блоки водоочистки, было установлено, что интегральное отклонение от оптимальных значений оказалось значительно ниже среднеарифметического по отдельным блокам и составляет $31,7 \%$.

Это можно объяснить взаимным влиянием модулей. Компенсировать данное влияние бывает затруднительно по следующим причинам:

- связывание различных модулей водоочистки в один комплекс требует дополнительного использования средств контроля, однако во многих случаях датчиков с требуемыми параметрами просто не существует; например, между модулями «окислители» - «электролизер» (выполняет функции электрокоагулятора) надо проводить измерения БПК 5 быстродействием не менее 1,5 секунды и периодом 25 секунд, а таких измерительных средств промышленностью не выпускается (даже для лабораторного использования); 
Вестник Брестского государственного технического университета. 2020. №4

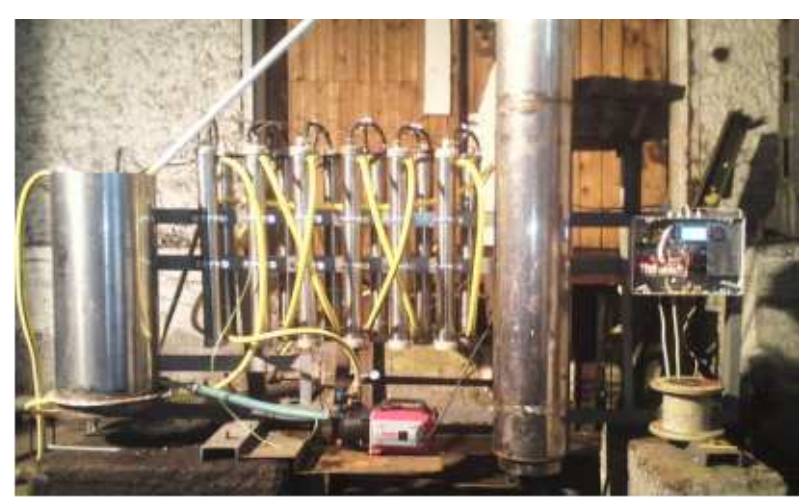

A)

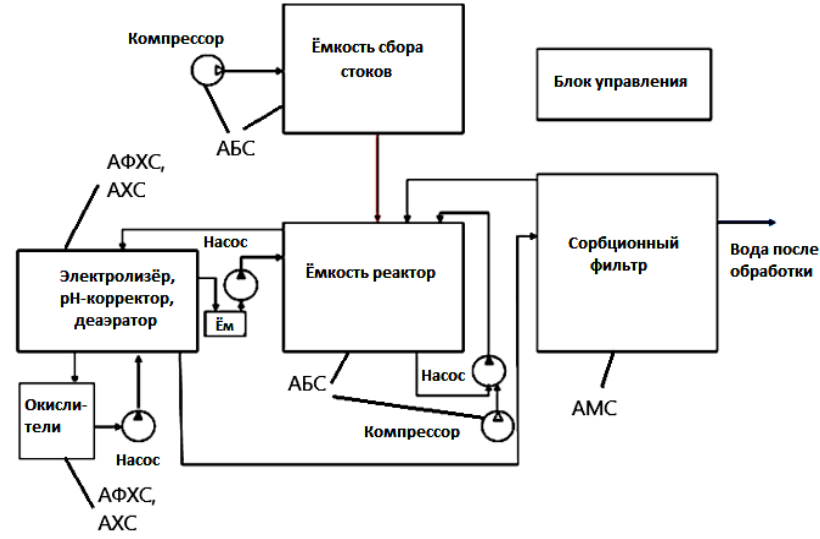

Б)

АФХС - агрегат физико-химического способа, АХС - агрегат химического способа, AMC - агрегат механического способа, АБС - агрегат биологического способа

А - внешний вид, Б - структурная схема системы водоочистки

Рисунок 3 - Комбинированная система водоочистки с реализацией разных способов удаления загрязнителей

Таблица 2 - Отклонение фактической степени автоматизации модулей комбинированной системы водоочистки от оптимальных значений (с учетом выполнения заданных ТП одним технологическим узлом)

\begin{tabular}{|c|c|}
\hline $\begin{array}{c}\text { Название оборудования } \\
\text { водоочистки }\end{array}$ & $\begin{array}{c}\text { Соответствие степени } \\
\text { автоматизации оптимальному } \\
\text { значению, S }\end{array}$ \\
\hline Электрокоагуляция & $54,3 \%$ \\
\hline Аэрация & $64,6 \%$ \\
\hline Фильтрация & $71,3 \%$ \\
\hline Электрохимическое окисления & $34,2 \%$ \\
\hline Электрохимическая рН-коррекция & $53,4 \%$ \\
\hline
\end{tabular}

- практически полное отсутствие методической базы для анализа взаимного влияния различных способов удаления загрязнителей из водных растворов в промышленных условиях (особенно в режиме реального времени).

Имитационный статистический анализ также выявил неодинаковое влияние связей между различными модулями. При такой оценке условно менялось количество эфффективных (промышленно выпускаемых) датчиков - для определения влияния связей на эффрективность автоматизации.

Установлено, что максимальное влияние на интегральный критерий оценки эффрективности автоматизации предоставляют связи между блоками со значительной электро-технологической интенсификацией ТП, где необходима оперативная передача информации на блок управления с согласованием режимных параметров (связи «рН-коррекция - окисление», «рН-коррекция - фильтрация »). что системы водоочистки представляют собой сложные многопараметрические объекты, при функционировании которых в режиме реального времени возникает задача координации работы управляемых подсистем. Решением данной задачи является определение способа взаимодействия подсистем, при котором управления, оптимальные по критериям экологической эффективности для каждой из подсистем, являются оптимальными по общему критерию для процесса в целом.

Задача является еще более сложной, если критерий оптимизации помимо качества очистки учитывает также энергоэффективность системы [6].

\section{Заключение}

На основе анализа эффрективности автоматизации существующих систем водоочистки установлено, что общий эффект от автоматизации не является простой суммой эффектов от автоматизации отдельных подсистем и может быть существенно ниже. Это можно объяснить взаимным влиянием подсистем, которое не всегда в должной степени учитывается. При этом влияние отдельных подсистем также неодинаково.

В частности, среднее значение фактической эффрективности автоматизации модулей водоочистного оборудования относительно оптимальных значений для рассмотренных пяти технологических решений (аэрация, фильтрация, электрокоагуляция, электрохимические окисление и рН-коррекция) составляет $55,56 \%$, в то время как для единого комплекса электротехнических средств (системы водоочистки в целом) оно оказалось значительно ниже $(31,7 \%)$.

Таким образом, выбор структуры и состава системы управления процессом водоочистки должен осуществляться на основе анализа эффективности автоматизации отдельных подсистем с учетом возможности организации тесной взаимосвязи между отдельными подсистемами. Для этого может понадобиться дополнительная разработка измерительных комплексов, способных работать в промышленных условиях на реальных объектах водоотведения в режиме реального времени.

При работе в нештатных ситуациях состав сточных вод может скачкообразно изменяться, что приведет к изменению влияния отдельных подсистем на качество водоочистки. Система управления должна обладать способностью самонастройки, т. е. относится к классу интеллектуальных систем. Перспективным направлением дальнейшего развития эффективных систем водоочистки может являться применение математических методов системного анализа с использованием, например, информационно-функциональных моделей.

\section{Список цитированных источников}

1. Мазоренко, Д. І. Інженерна екологія сільськогосподарського виробництва / Д. І. Мазоренко, В. Г. Цапко, Ф.І.Гончаров - К. : Знання, $2006-376 \mathrm{c.}$.

2. Adav, S. Aerobic granular sludge: Recent advances / S. Adav, D. Lee, K. Show, J. Tay // Biotechnology Advances. - 2008. № 26(5). - P. 411-423.

3. Bolzonella, D. Anaerobic co-digestion of sludge with other organic wastes and phosphorus reclamation in wastewater treatment plants for biological nutrients removal / D. Bolzonella, P. Pavan, P. Battistoni, F. Cecchi // Water Science \&amp; Technology. - 2006. - № 53(12). - P. 177.

4. Kawamura, S. Integrated design and operation of water treatment facilities - 2nd ed. - New York : John Wiley, 2000. - Srivastava, V. C. Treatment of pulp and paper mill wastewaters with Polyaluminium chloride and bagasse fly ash, Colloids and Surface / V. C. Srivastava, I. D. Mall, I. M. Mishra // A. Physiochemical Engineering Aspects. - 2005. - Vol. 260. - P. 17-28. 
5. Вертай, С. П. Обоснование структуры и заданий системы поддержки принятия решений обобщённой оценки перспективности инновационных технологий / С.П.Вертай, В.Н.Штепа // Науковий вісник Національного університету біоресурсів і природокористування України. - Серія : Техніка та енергетика АПК. - Київ: Видавничий центр НУБіП України, 2016. - Вип. 240. - С. 86-93.

6. Штепа, В. Н. Концепция управления оборудованием водоочистки с учетом доминирующего загрязнителя / В. Н. Штепа, А. П. Левчук // Агропанорама: научно-технический журнал. - 2018. № 5. - C. 33-38.

7. Штепа, В. М. Обгрунтування та розробка критерію енергоефрективності функціонування електротехнологічних систем водопідготовки / В. М. Штепа, Ф. І. Гончаров, М. А. Сироватка // Науковий вісник Національного університету біоресурсів і природокористування України. - Серія: Техніка та енергетика АПК: збірник наукових праць. - Київ : НУБіПУ, 2011. - Вип. 161. - С. 187-193.

8. Штепа, В. М. Обгрунтування робочої міри ефективності електротехнологічної водоочистки / В. М. Штепа // Енергетика і автоматика. - 2018. - № 4. - С. 99-111. [Електронний ресурс]. - Режим доступу : http://journals.nubip.edu.ua/index.php/Energiya/article/ view/11558. - Дата доступу : 16.10.2019.

9. Штепа, В. Н. Вероятностные нейронные сети в задачах управления комбинированными системами водоочистки / В. Н. Штепа, Н. А. Заец, О. Н. Прокопеня, Н. Н. Луцкая // Вестник Брестского государственного технического университета. - 2018. № 2(110) : Водохозяйственное строительство, теплоэнергетика и геоэкология. - С. 88-90.

\section{References}

1. Mazorenko, D. I. Inzhenerna ekologiya sil's'kogospodars'kogo virobnictva / D. I. Mazorenko, V. G. Capko, F. I. Goncharov K. : Znannya, 2006 - 376 s.

2. Adav, S. Aerobic granular sludge: Recent advances / S. Adav, D. Lee, K. Show, J. Tay // Biotechnology Advances. - 2008. № 26(5). - P. 411-423.

3. Bolzonella, D. Anaerobic co-digestion of sludge with other organic wastes and phosphorus reclamation in wastewater treatment plants for biological nutrients removal / D. Bolzonella, P. Pavan, P. Battistoni, F. Cecchi // Water Science \& Technology. - 2006. № 53(12). - P. 177.

4. Kawamura, S. Integrated design and operation of water treatment facilities - 2nd ed. - New York : John Wiley, 2000. Srivastava, V. C. Treatment of pulp and paper mill wastewaters with Polyaluminium chloride and bagasse fly ash, Colloids and Surface / V. C. Srivastava, I. D. Mall, I. M. Mishra // A. Physiochemical Engineering Aspects. - 2005. - Vol. 260. - R. 17-28.

5. Vertaj, S. P. Obosnovanie struktury i zadanij sistemy podderzhki prinyatiya reshenij obobshchyonnoj ocenki perspektivnosti innovacionnyh tekhnologij / S. P. Vertaj, V. N. SHtepa // Naukovij visnik Nacional'nogo universitetu bioresursiv i prirodokoristuvannya Ukraïni. - Seriya : Tekhnika ta energetika APK. - Kiï: Vidavnichij centr NUBiP Ukraïni, 2016. - Vip. 240. - S. 86-93.

6. SHtepa, V. N. Koncepciya upravleniya oborudovaniem vodoochistki s uchetom dominiruyushchego zagryaznitelya / V. N. SHtepa, A. P. Levchuk // Agropanorama: nauchno-tekhnicheskij zhurnal. 2018. - № 5. - S. 33-38.

7. SHtepa, V. M. Obgruntuvannya ta rozrobka kriteriyu energoefektivnosti funkcionuvannya elektrotekhnologichnih sistem vodopidgotovki I V. M. SHtepa, F. I. Goncharov, M. A. Sirovatka // Naukovij visnik Nacional'nogo universitetu bioresursiv i prirodokoristuvannya Ukraïni. Seriya: Tekhnika ta energetika APK: zbirnik naukovih prac'. - Kiïv : NUBiPU, 2011. - Vip. 161. - S. 187-193.

8. SHtepa, V. M. Obgruntuvannya robochoï miri efektivnosti elektrotekhnologichnoï vodoochistki / V. M. SHtepa // Energetika i avtomatika. - 2018. - № 4. - S. 99-111. [Elektronnij resurs]. Rezhim dostupu : http://journals.nubip.edu.ua/index.php/Energiya/ article/view/11558. - Data dostupu : 16.10.2019.

9. SHtepa, V. N. Veroyatnostnye nejronnye seti v zadachah upravleniya kombinirovannymi sistemami vodoochistki / V. N. SHtepa, N. A. Zaec, O. N. Prokopenya, N. N. Luckaya // Vestnik Brestskogo gosudarstvennogo tekhnicheskogo universiteta. - 2018. - № 2 (110) : Vodohozyajstvennoe stroitel'stvo, teploenergetika i geoekologiya. S. $88-90$ 